\title{
Increased diastolic blood pressure response to exercise testing when coronary artery disease is suspected An indication of severity
}

\author{
FAWAZ AKHRAS, JAMES UPWARD, GRAHAM JACKSON \\ From the Department of Cardiology, King's College and Lewisham Hospitals, London
}

SUMMARY One hundred and two consecutive patients with a history of chest pain or recent previous myocardial infarction underwent maximal treadmill stress testing and coronary angiography. The diastolic blood pressure response to exercise was evaluated independently of ST segment change and systolic blood pressure. In the presence of a normal systolic blood pressure response an increase in diastolic blood pressure of $15 \mathrm{~mm} \mathrm{Hg}$ on at least two determinations during the same stage of exercise was considered abnormal. In 99 patients an accurate diastolic reading was possible. Of these, 61 had a normal diastolic blood pressure response; in 25 of these the ST segment was ischaemic and seven had three vessel coronary artery disease. Thirty eight patients had an abnormal diastolic blood pressure response and 27 of these had an ischaemic ST response. Of the 11 with a negative ST response for ischaemia one had left main stem disease, seven three vessel disease, and three two vessel disease. Patients with an abnormal diastolic response had greater ST depression with more angina at a reduced workload than those with a normal diastolic response.

In patients with chest pain an abnormal increase in diastolic blood pressure on exercise reflects severe coronary artery disease. Although no false positives occurred in this study there was an appreciable number of false negatives (sensitivity $46 \%$ ) in both patients with chest pain and those with infarction. An abnormal diastolic response therefore represents a useful additional diagnostic indicator of coronary artery disease when the ST segment response is normal or borderline. When the diastolic pressure becomes increased with or without ST changes the likelihood of severe coronary artery disease is increased.

Normally during exercise the diastolic blood pressure decreases owing to a fall in the systemic vascular resistance secondary to peripheral vasodilatation.' Previous studies have shown that the response of the systolic blood pressure to exercise testing has its own useful diagnostic implications. There is normally a graded rise during maximal exercise treadmill testing, whereas a failure to rise or a fall during exercise suggests significant left ventricular ischaemia. ${ }^{2-5}$ At present, ST segment abnormalities, the systolic blood pressure response, and angina are accepted variables for assessing the results of exercise testing. Nevertheless, there remain some borderline cases in which

Requests for reprints to Dr Graham Jackson, Department of Cardiology, King's College Hospital, Denmark Hill, London, SE5 9RS.

Accepted for publication 5 January 1985 interpretation is difficult and an indication of the severity of underlying disease uncertain.

In looking for other diagnostic variables we hypothesised that a severely ischaemic left ventricle might on exercise suffer a sufficient fall in cardiac output that a reflex increase in peripheral resistance would increase the diastolic blood pressure. We were supported in the hypothesis by the animal work of Coote and his colleagues ${ }^{6}$ and additional experimentàtion in man..$^{7-10} \mathrm{We}$ therefore evaluated the diastolic blood pressure response to exercise in 102 patients with chest pain looking at its independent diagnostic role but more importantly at its additive position with regard to the established ST and systolic blood pressure criteria. We were particularly concerned to prove or disprove its theoretical physiological reflection of significant ischaemia. 


\section{Patients and methods}

\section{STUDY POPULATION}

One hundred and two patients were studied. Twenty were undergoing routine assessment after myocardial infarction, and the remaining 82 had chest pain believed to be of cardiac origin. All were studied by maximal treadmill stress testing using 12 lead electrocardiography, and coronary angiography. Table 1 shows the patients' characteristics and clinical data. Unly patients with a normal resting blood pressure were included. No patient received cardioactive drugs for 48 hours before the tests, and none was taking digoxin.

\section{EXERCISE TESTING}

Control electrocardiograms and blood pressure measurements were obtained with the patient standing. Twelve lead treadmill stress testing was performed, adopting the Bruce protocol." Electrocardiograms were obtained at one and three minutes of each stage of the protocol, at peak exercise, and $1,2,3$, and 5 minutes into the recovery period. The recordings were made with a fully automated programmable three channel electrocardiograph (Marquette Instrument Co, Model 1800 Treadmill EC MAC' 1) complying with American Heart Association standards. The ST response was considered abnormal if $\geqslant 1 \mathrm{~mm}$ of downsloping ST depression persisted for five consecutive complexes $0.08 \mathrm{~s}$ beyond the $\mathrm{R}$ wave. Blood pressure was recorded by a standard sphygomomanometer cuff technique before, during, and after exercise. Diastolic blood pressure was measured at phase V. A normal response was defined as no change or a decrease in diastolic blood pressure associated with a rising systolic blood pressure. An abnormal response was defined as an increase of $\geqslant 15 \mathrm{~mm} \mathrm{Hg}$ in diastolic blood pressure on two separate determinations during the same stage of exercise. The mean of two separate exercise determinations at peak exercise and $<20 \mathrm{~s}$ into recovery was used to calculate the change in diastolic blood pressure from baseline. Diastolic pressure could not be accurately measured in three patients, leaving 99 patients available for further analysis.

\section{ANGIOGRAPHY}

All patients underwent cardiac catheterisation and coronary angiography within six to 10 weeks of the exercise test. A luminal narrowing of $>70 \%$ in any of the three coronary vessels was considered to be significant and used as the criterion for diagnosing coronary artery disease.

\section{STATISTICAL ANALYSIS}

Clinical, exercise, and coronary angiographic data on the 99 patients are expressed as mean (SEM) or mean (SD). Differences between continuous variables were assessed by the two tail $t$ test and unpaired $t$ test.

\section{Results}

\section{EXERCISE DATA}

In 38 patients the diastolic blood pressure response to exercise was classified as abnormal, and in 61 the response was normal. Of those with an abnormal diastolic response, the specificity was $100 \%$ with no false positive cases of coronary artery disease. The sensitivity was $46 \%$ with a predictive value of $46 \%$. Of those with a normal diastolic response and coronary artery disease, 24 had single vessel disease, and in 20 of these it subtended a previous myocardial infarction. With regard to disease greater than single vessel disease the sensitivity was $65 \%$ and predictive value $61 \%$.

The ST responses judged independently gave a specificity of $65 \%$ and sensitivity of $32 \%$. A negative exercise ST response, however, occurred in 20 of 22 patients with single vessel disease subtending a previous myocardial infarction. In this setting the $S T$ response was accurately predicting the absence of additional disease. The degree of ST abnormality was greater in patients with an abnormal diastolic response $(1.48(1.7)$ vs $0.93(0.16) \mathrm{mm}, \mathrm{p}<0.05)$ (Fig. 1). In addition, there were more patients developing angina at a reduced exercise time in the group with an abnormal diastolic response than in that with a normal response $(5.3(1.8)$ vs 7.6 (1.7) $\mathrm{min}, \mathrm{p}<0.001$ ) (Fig. 2). Eleven of the 38 patients with an abnormal diastolic response had no significant ST change on exercise. Angiography showed significant coronary artery dis-

Table 1 Patients' characteristics and clinical data

\begin{tabular}{|c|c|c|c|}
\hline & $\begin{array}{l}\text { Normal response } \\
(n=61)\end{array}$ & $\begin{array}{l}\text { Abnormal response } \\
(n=38)\end{array}$ & p value \\
\hline $\begin{array}{l}\text { Mean (SD) age (yr) } \\
\text { Sex (\% of males) } \\
\text { No (\%) with previous myocardial infarction } \\
\text { Mean (SD) resting heart rate (beats/min) } \\
\text { Mean (SD) resting blood pressure ( } \mathrm{mm} \text { Hg) }\end{array}$ & $\begin{array}{l}48(8) \\
89 \\
35(57 \%) \\
84(3)\end{array}$ & $\begin{array}{l}51(7) \\
87 \\
22(58 \%) \\
86(2)\end{array}$ & $\begin{array}{l}\text { NS } \\
\text { NS } \\
\text { NS } \\
\text { NS }\end{array}$ \\
\hline $\begin{array}{l}\text { Systolic } \\
\text { Diastolic }\end{array}$ & $\begin{array}{c}126(17) \\
79(8)\end{array}$ & $\begin{array}{c}136(17) \\
82(8)\end{array}$ & $\begin{array}{l}\text { NS } \\
\text { NS }\end{array}$ \\
\hline
\end{tabular}



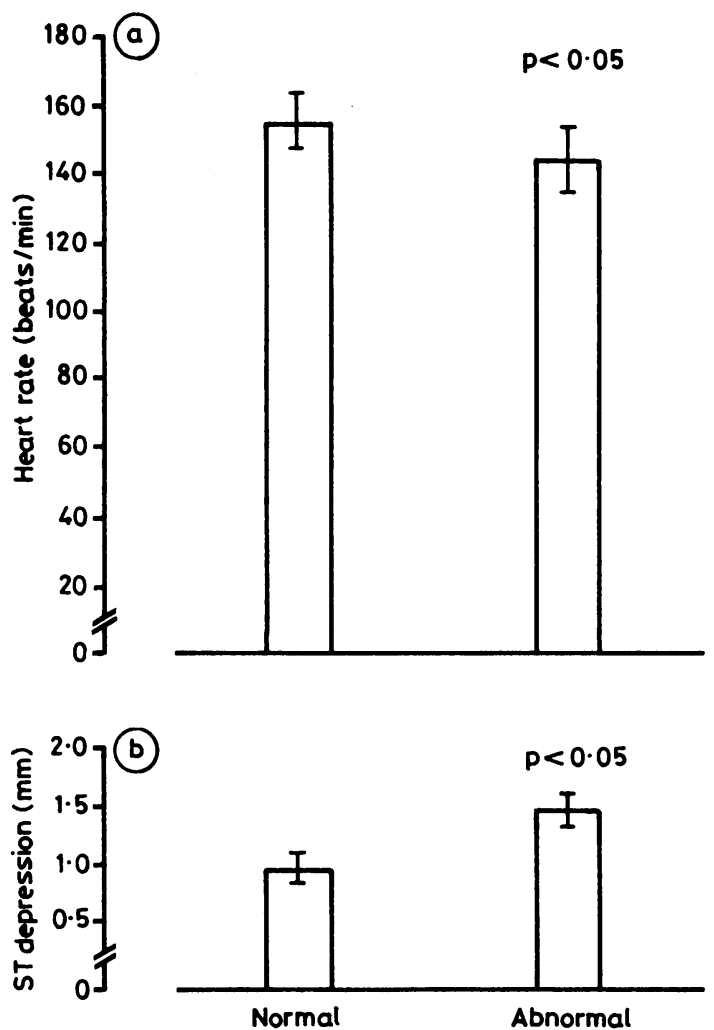

Fig. 1 (a) Heart rate and (b) ST segment depression at peak exercise in patients with normal and abnormal diastolic blood pressure response to exercise.

ease in all 11 patients.

The systolic blood pressure response was normal for both groups. In those with a normal diastolic response the mean systolic blood pressure rose from 126 (17) to 151 (25) $\mathrm{mm} \mathrm{Hg}$ and in those with an abnormal diastolic response from 136 (17) to 163 (24) $\mathrm{mm} \mathrm{Hg}$ (NS).

\section{ANGIOGRAPHIC DATA}

At angiography, of the 61 patients who had a normal

Table 2 Prevalence (\%) of coronary artery disease in 38 patients with abnormal diastolic blood pressure and in 61 with normal diastolic blood pressure response to exercise

\begin{tabular}{lll}
\hline $\begin{array}{l}\text { Coronary artery } \\
\text { disease }\end{array}$ & Abnormal & Normal \\
\hline One to two vessel & 24 & 61 \\
Three vessel & 71 & 11 \\
Left main stem & 5 & 0 \\
Non-significant & 0 & 28 \\
\hline
\end{tabular}
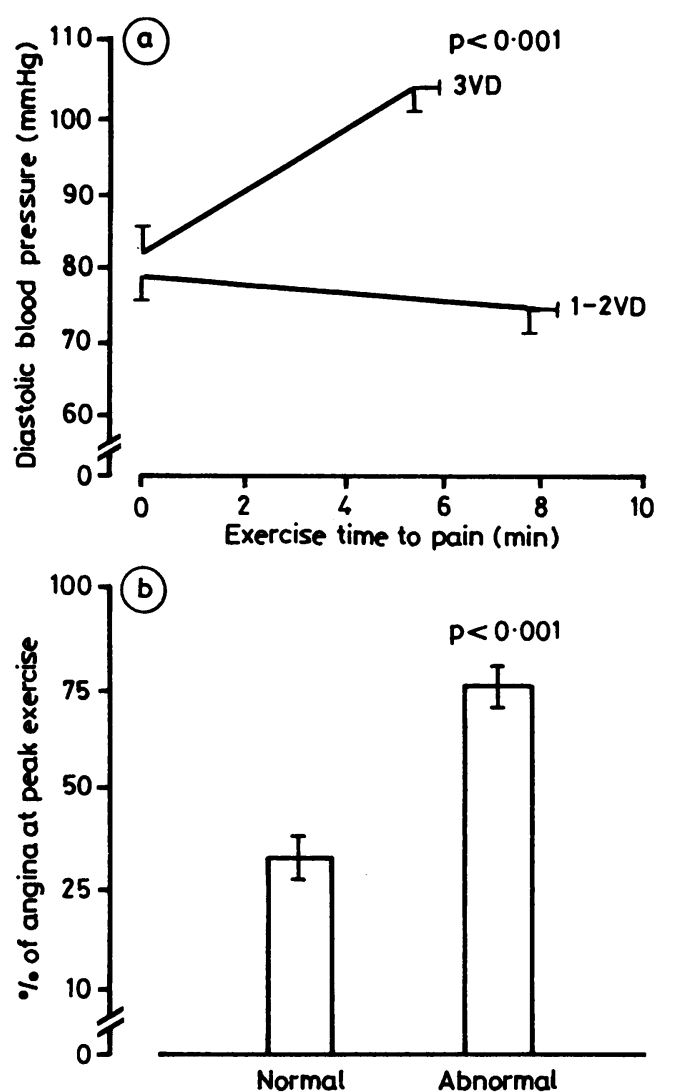

Fig. 2 (a) Exercise time to pain and (b) percentage of angina occurring at peak exercise in patients with normal and abnormal diastolic blood pressure response to exercise. VD, vessel disease.

diastolic blood pressure response to exercise, $37(61 \%)$ had one or two vessel coronary disease, seven (11\%) three vessel coronary disease, and the remaining 17 (28\%) non-significant coronary lesions (Table 2). In contrast, $29(76 \%)$ of the 38 patients with an abnormal diastolic blood pressure response had three vessel or left main stem coronary disease, and only nine (24\%) had two vessel coronary disease. The difference in the proportion of patients in each group with no significant coronary artery lesion and three vessel or left main stem coronary artery disease was significant $(p<0.02)$, and when the disease in each group was compared with the results of the diastolic pressure response the difference became highly significant $(p<0.001)$. Thus, those patients with an abnormal diastolic blood pressure response to exercise were more likely to have severe coronary artery disease than those with a normal response. The number of patients who had segmental contraction abnormalities on left ventriculography was similar in both groups. 


\section{Discussion}

In the assessment of chest pain believed to be of cardiac origin the exercise electrocardiogram is of diagnostic and prognostic importance. The ST segment response alone indicates a sensitivity of between $78 \%$ and $96 \%$, with a specificity averaging $90 \% .{ }^{1213}$ Differences in technique and patient selection explain the variability with Fox et al who achieved better figures with precordial mapping. ${ }^{13}$ Because many of our patients had single vessel disease subtending a previous infarct and no additional ischaemia our sensitivity figures including this group were poor at $32 \%$. When allowance is made for this subgroup, however, the figure rises to a more acceptable $79 \%$.

As this was a prospective study of consecutive exercise tests a major variability in patient selection occurred. We were principally addressing the concept of severe ischaemia so compromising left ventricular function that diastolic pressure would rise secondary to increased peripheral vasoconstriction. Our observations support this hypothesis, but by diluting our cases with the less severe we have fortunately been able to place the role of the diastolic pressure in perspective. Firstly, it is essential to define raised diastolic pressure. We selected $15 \mathrm{~mm} \mathrm{Hg}$ for two reasons; firstly, we found it difficult in the clinical setting to assess accurately the diastolic pressure within 5-10 $\mathrm{mm} \mathrm{Hg}$ of baseline, and, secondly, Wolthuis et al, studying normal adults, concluded that any rise or fall in diastolic pressure was unlikely to exceed 10 mm Hg. ${ }^{1}$

Previous studies make little reference to the diastolic blood pressure measurements during exercise other than to confirm the tendency to fall secondary to systemic vasodilatation. ${ }^{13}$ Emphasis is on a fall in systolic pressure of $\geqslant 10 \mathrm{~mm} \mathrm{Hg}{ }^{14}$ reflecting severe two or three vessel disease rather than single vessel disease. ${ }^{15}$ We speculated that before this fall occurs compensatory vasoconstriction might increase the diastolic pressure so warning of imminent left ventricular compromise.
Addressing the role of the diastolic response alone in diagnosis it is clear that it is limited by the large number of false negatives. When abnormal, however, it appears to be $100 \%$ accurate in identifying underlying significant disease. It may be, of course, that it merely reflects significant left ventricular dysfunction from any cause, and we would expect an incidence of false positives for coronary artery disease but true positives for left ventricular compromise to develop with more diffuse populations studied. In patients with chest pain it is therefore primarily an index of severity reflecting significant left ventricular dysfunction secondary to ischaemia and perhaps urgency with a view to angiographic evaluation.

Combining the diastolic response with the ST response adds a valuable diagnostic variable. In those with a normal diastolic response and two or three vessel coronary artery disease the exercise ST response failed to detect one of 19 patients (Table 3). In those with an abnormal diastolic response the ST change alone failed to identify 11 of $38(29 \%)$ patients. In all of these the diastolic response was abnormal and the severity of the problem identified. It may be argued that this ST response is poor, and we would agree. Nevertheless, the abnormal diastolic group suffered more pain at a lower workload, and it is possible that in this situation the diastolic changes preceded the ST changes because the primary reflection of ischaemia was a profound fall in cardiac output. We excluded patients with an abnormal systolic blood pressure response so that the diastolic pressure changes could be viewed independently.

In conclusion, in patients with chest pain we believe an abnormal diastolic blood pressure rise of $\geqslant 15 \mathrm{~mm} \mathrm{Hg}$ is a useful and important index of underlying significant coronary artery disease. It is additive to the previously accepted variables, and with regard to patient selection for further investigations it may help in the identification of high risk patients who warrant early invasive study. Furthermore, in those in whom the conventional variables of exercise testing are of borderline value an increased diastolic response

Table 3 Correlation between exercise electrocardiographic (ECG) variables and coronary angiography. Figures are numbers of patients

\begin{tabular}{|c|c|c|c|c|c|}
\hline \multirow{2}{*}{$\begin{array}{l}\text { Exercise test } \\
\text { variables }\end{array}$} & \multicolumn{4}{|c|}{ Coronary angiography } & \multirow[t]{2}{*}{ Total } \\
\hline & $3 V D$ and $L M$ & $2 V D$ & $I V D$ & $N C A$ & \\
\hline $\begin{array}{l}\text { Normal diastolic blood pressure and: } \\
\text { Positive ECG } \\
\text { Negative ECG }\end{array}$ & $\begin{array}{l}7 \\
0\end{array}$ & $\begin{array}{r}12 \\
1\end{array}$ & $\begin{array}{c}2 \\
22^{\star}\end{array}$ & $\begin{array}{r}6 \\
11\end{array}$ & $\begin{array}{l}27 \\
34\end{array}$ \\
\hline $\begin{array}{l}\text { Abnormal diastolic blood pressure and: } \\
\text { Positive ECG } \\
\text { Negative ECG } \\
\text { Total }\end{array}$ & $\begin{array}{r}21 \\
8 \\
36\end{array}$ & $\begin{array}{r}6 \\
3 \\
22\end{array}$ & $\begin{array}{r}0 \\
0 \\
24\end{array}$ & $\begin{array}{r}0 \\
0 \\
17\end{array}$ & $\begin{array}{l}27 \\
11 \\
99\end{array}$ \\
\hline
\end{tabular}

NCA, normal coronary artery.

$\star 20$ patients had previous infarction. 
should alert the physician to the possibility of significant coronary disease. The role of the diastolic blood pressure response in other diseases and its modification by interventions such as surgery merit further study, for if it reflects significant left ventricular dysfunction it could be a valuable prognostic marker.

\section{References}

1 Wolthuis RA, Froelicher VF, Fischer J, Triebwasser JH. The response of healthy men to treadmill exercise. Circulation 1977; 55: 153-7.

2 Irving JB, Bruce RA, DeRouen TA. Variations in and significance of systolic pressure during maximal exercise (treadmill) testing: relation to severity of coronary artery disease and cardiac mortality. Am $\mathcal{F}$ Cardiol 1977; 39: 841-8.

3 Morris SN, McHenry PL. The incidence and significance of exercise induced hypotension [Abstract]. Am $\mathcal{F}$ Cardiol 1977; 39: 289.

4 Bruce RA, DeRouen T, Peterson DR, et al. Noninvasive predictors of sudden cardiac death in men with coronary heart disease: predictive value of maximal stress testing. Am $\mathcal{F}$ Cardiol 1977; 39: 833-40.

5 Thomson PD, Kelemen MH. Hypotension accompanying the onset of exertional angina. A sign of severe compromise of left ventricular blood supply. Circulation 1975; 52: 28-32.

6 Coote JH, Hilton SM, Perez-Gonzalez JF. The reflex nature of the pressor response to muscular exercise. $\mathcal{F}$ Physiol (Lond) 1971; 215: 789-804.

7 Berne RM, Levy MN. Interplay of central and peripheral factors in the regulation of the circulation. In: Cardiovascular physiology. 2nd ed. St. Louis: CV Mosby, 1972: 237-53.

8 Alam M, Smirk FH. Observations in man on a pulse accelerating reflex from the voluntary muscle of the legs. f Physiol 1938; 92: 167-77.

9 Lind AR, McNicol GW, Donald KW. In: Evang K, Lange Andersen $\mathrm{K}$, eds. Physical activity in health and disease. Proceedings of international symposium of physical activity in health and disease. Boston: Williams and Wilkins, 1966:38-63.

10 Donald KW, Lind AR, McNicol GW, Humphreys PW, Taylor SH, Staunton HP. Cardiovascular responses to sustained (static) contractions. Circ Res 1967; 20: (suppl I) $15-32$.

11 Doan AE, Peterson DR, Blackmon JR, Bruce RA. Myocardial ischemia after maximal exercise in healthy men: a method for detecting potential coronary heart disease? Am Heart $\mathcal{F}$ 1965; 69: 11-21.

12 Mason RE, Likar I, Biern RO, Ross RS. Multiple-lead exercise electrocardiography. Experience in 107 normal subjects and 67 patients with angina pectoris, and comparison with coronary cine arteriography in 84 patients. Circulation 1967; 36: 517-25.

13 Fox KM, Selwyn AP, Oakley D, Shillingford JP. Relation between the precordial projection of S-T segment changes after exercise and coronary angiographic findings. Am $\mathcal{F}$ Cardiol 1979; 44: 1068-75.

14 Willerson JT, Hillis LD, Buja LM. Ischemic heart disease. New York: Raven Press, 1983: 171-9.

15 Morris SN, Phillips JF, Jordan JW, McHenry PL. Incidence and significance of decreases in systolic blood pressure during graded treadmill exercise testing. Am $\mathrm{f}$ Cardiol 1978; 41: 221-6. 